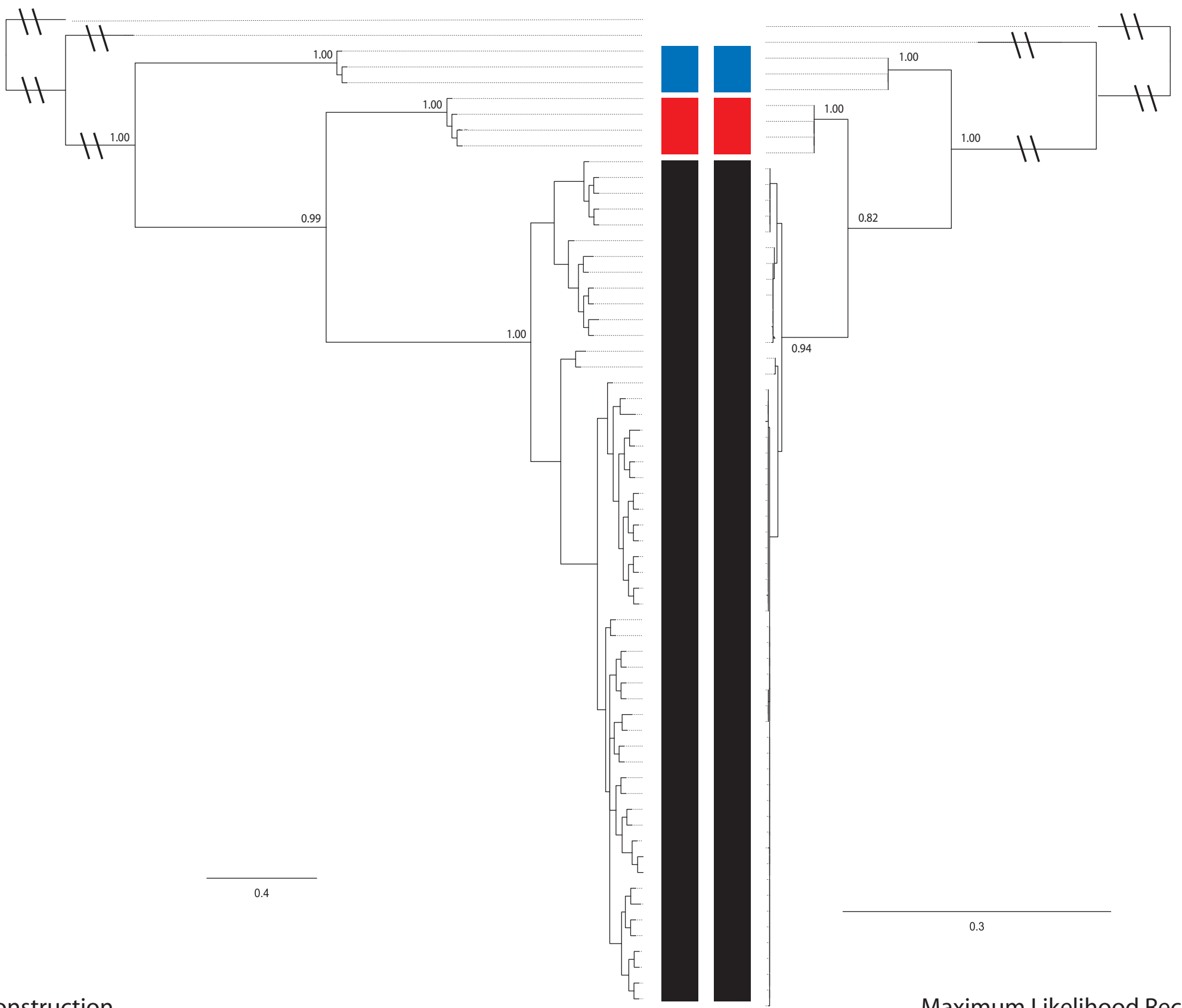

Maximum Likelihood Reconstruction 


\section{Saccopteryx bilineata}

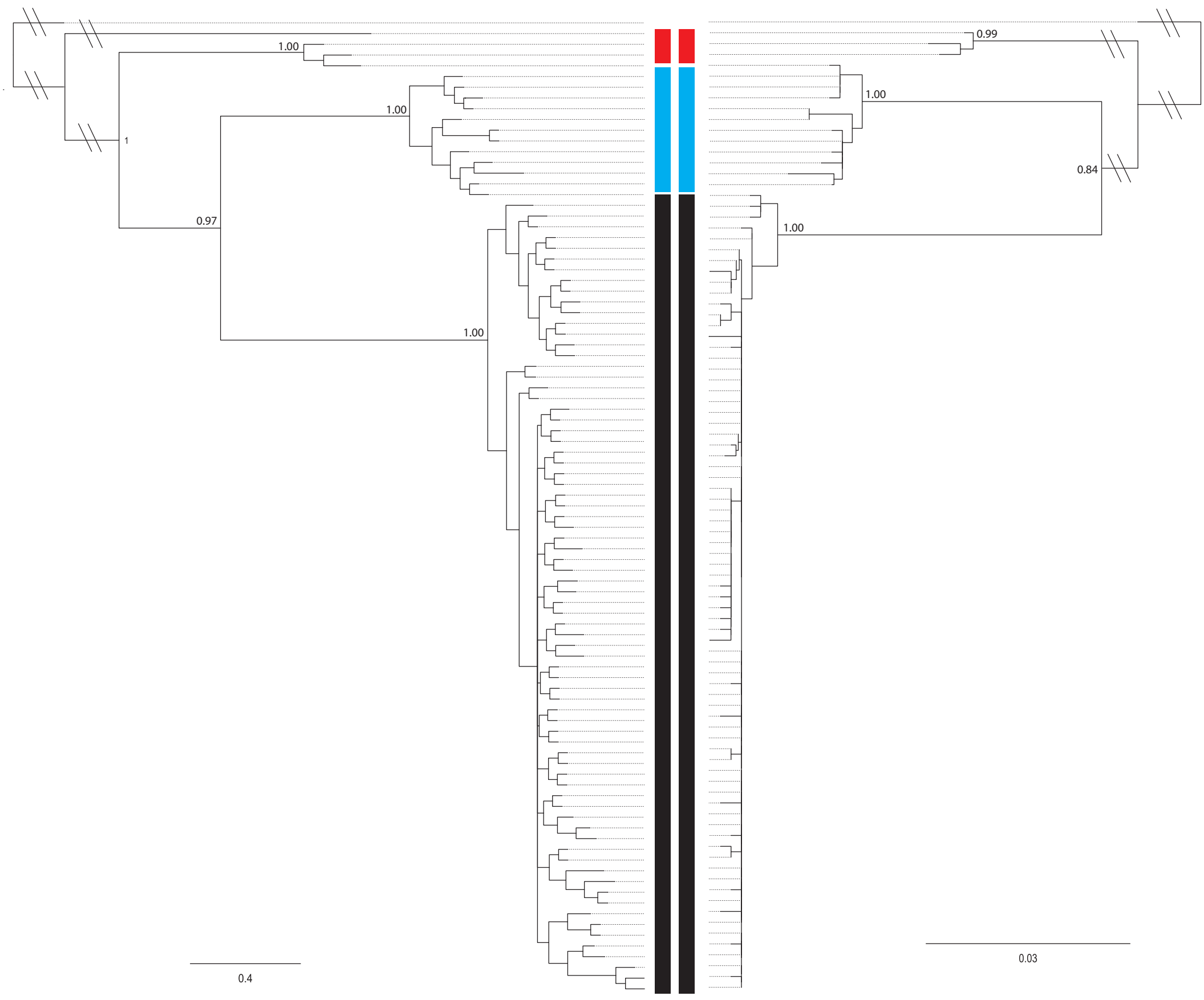




\section{Glossophaga soricina}

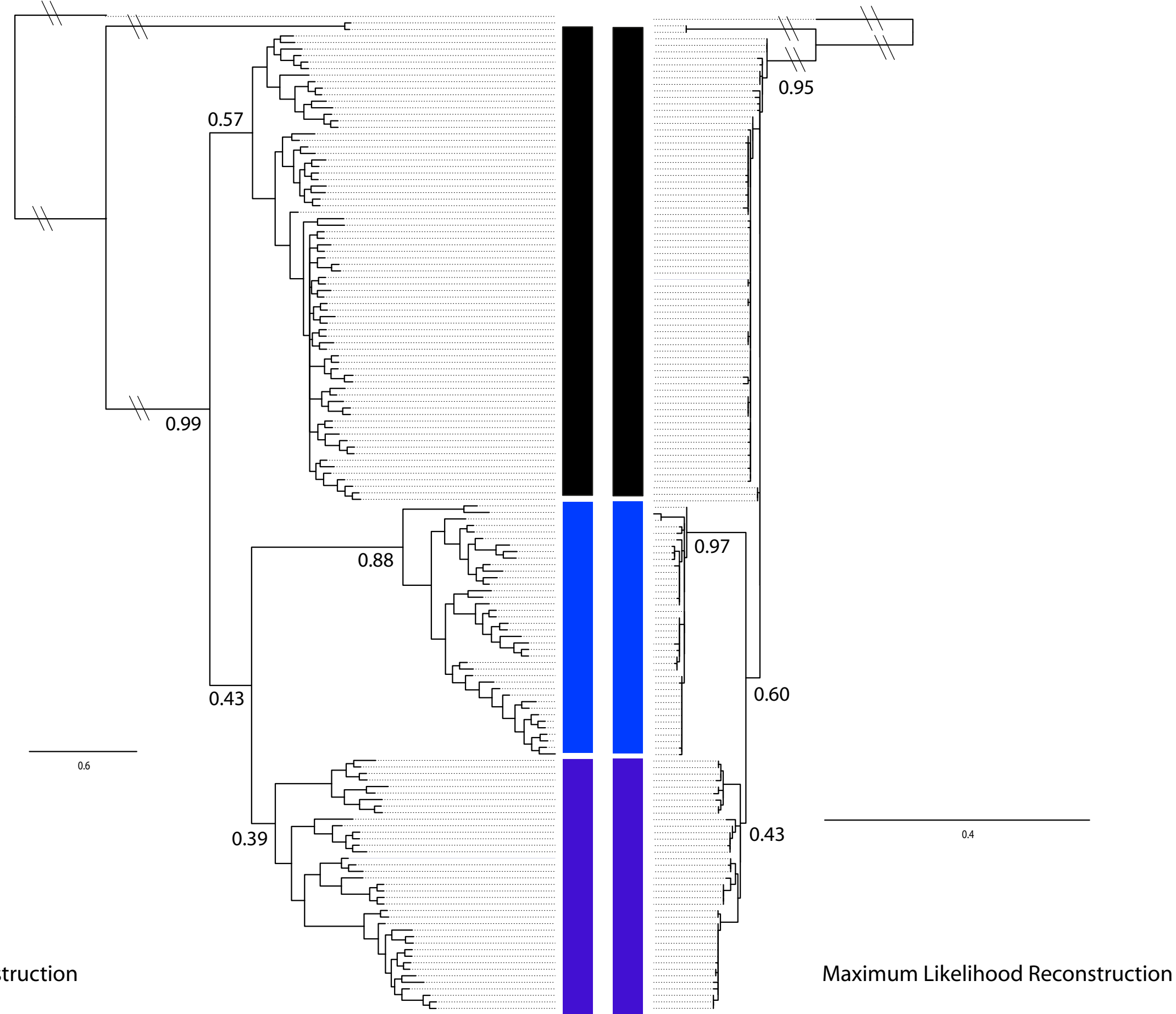




\section{Desmodus rotundus}

0.04

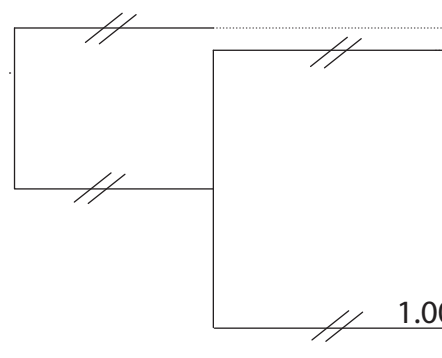

0.95
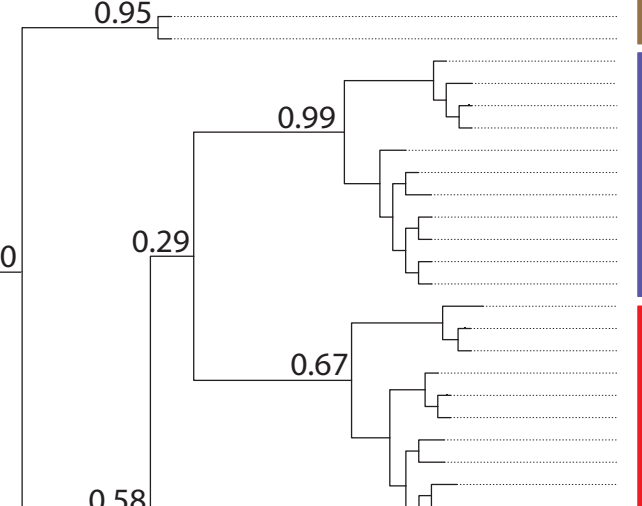

0.5
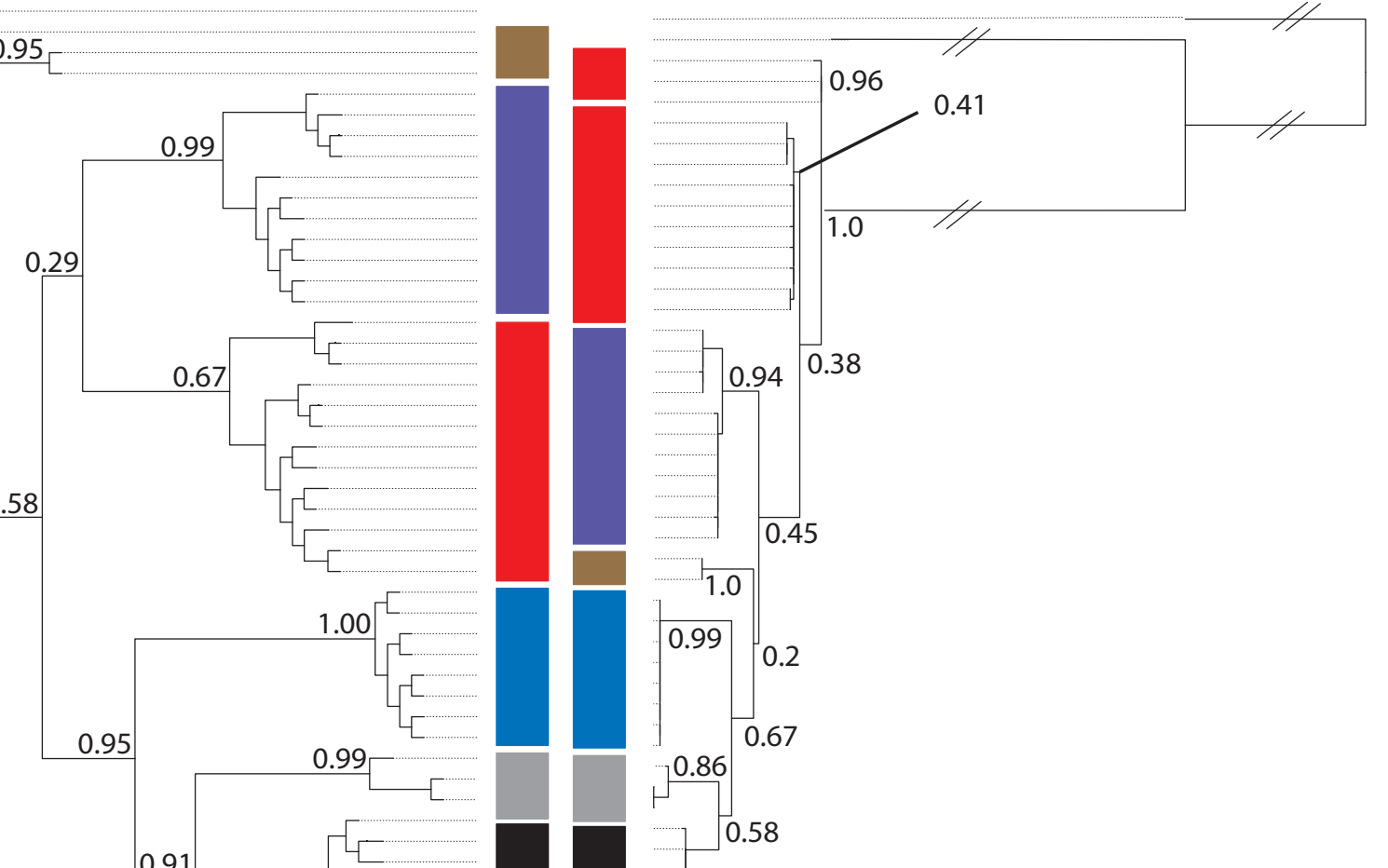

0.91

Bayesian Reconstruction

Maximum Likelihood Reconstruction 


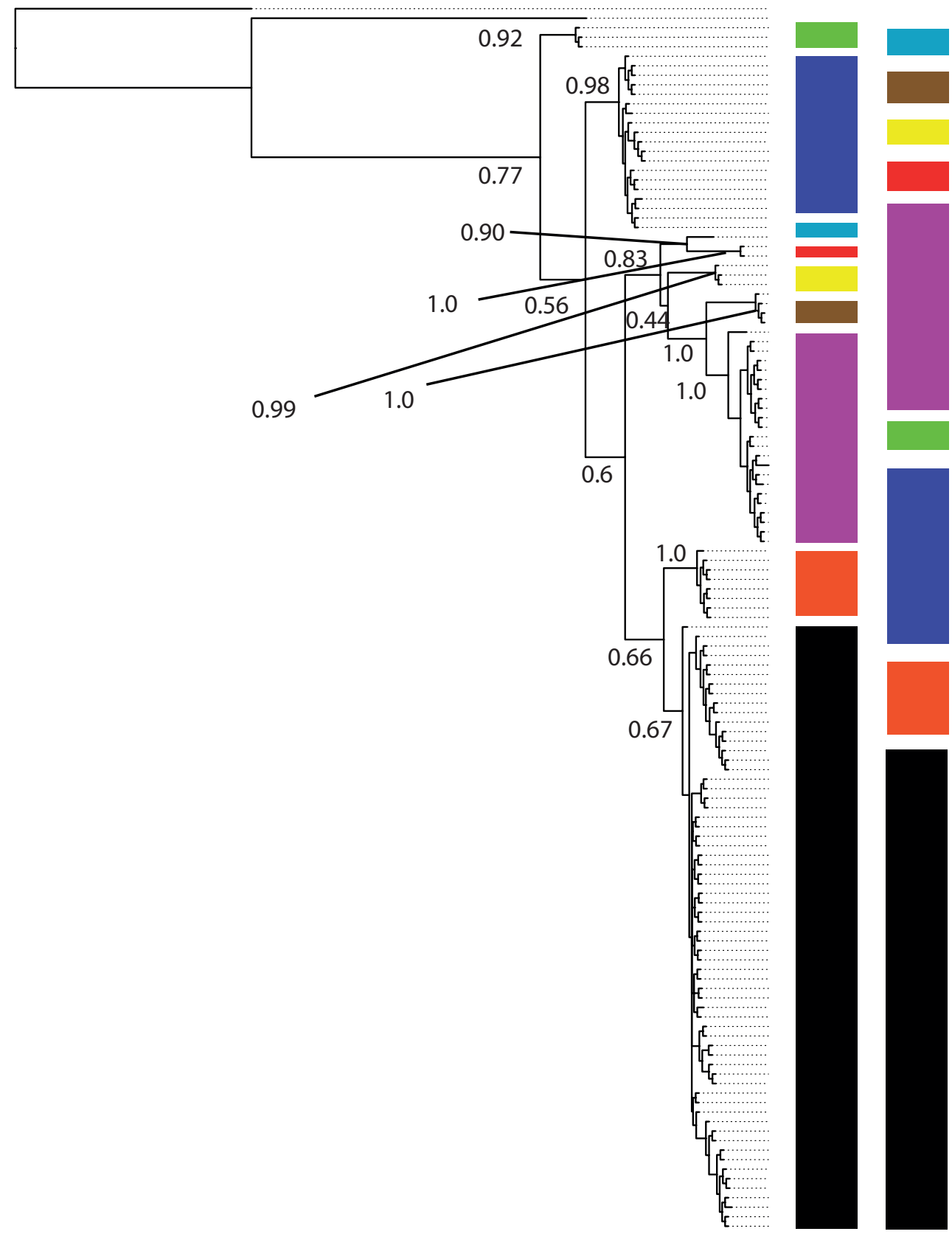

$\overline{0.6}$ 

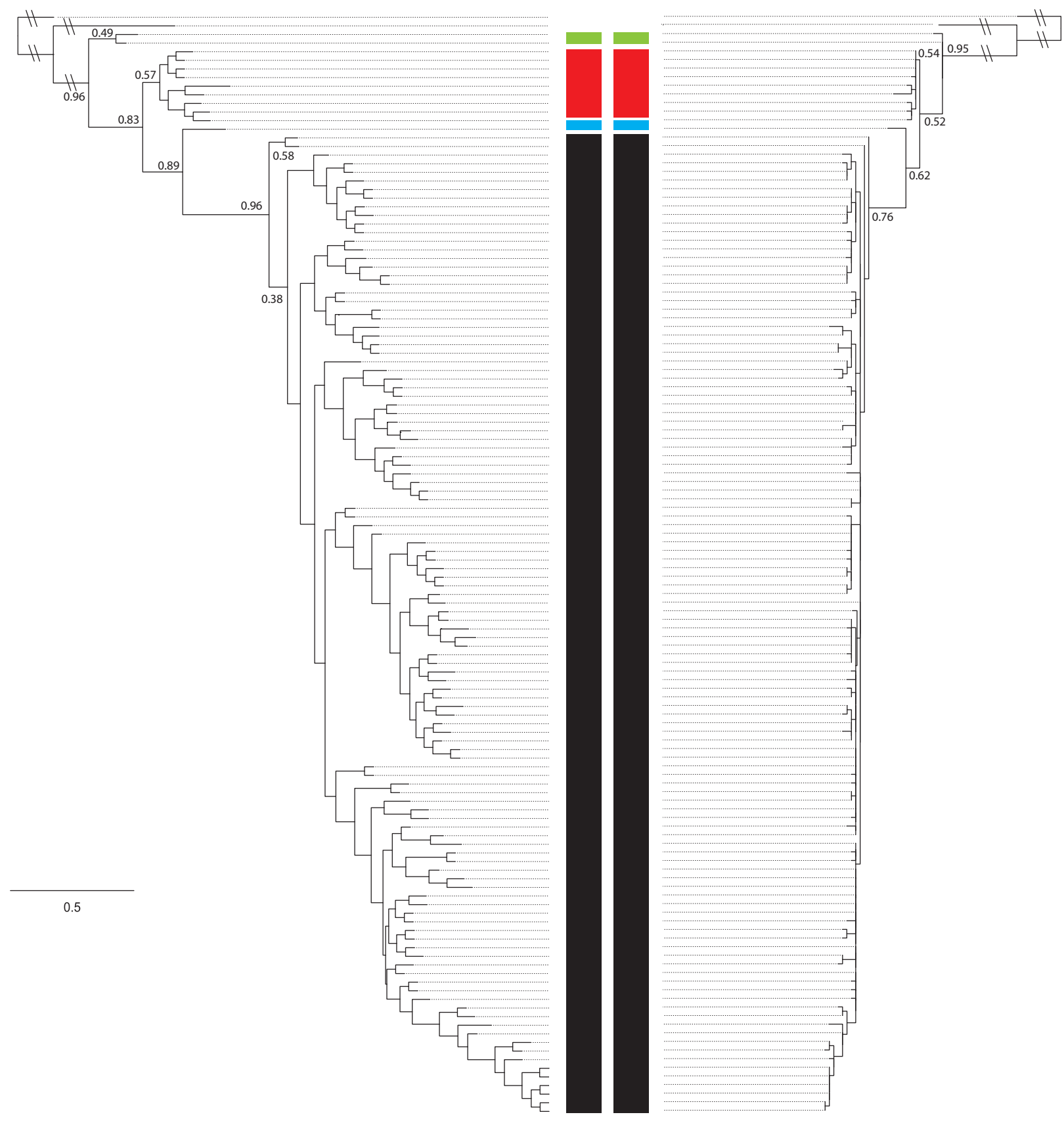

Bayesian Reconstruction 


\section{Micronycteris megalotis}

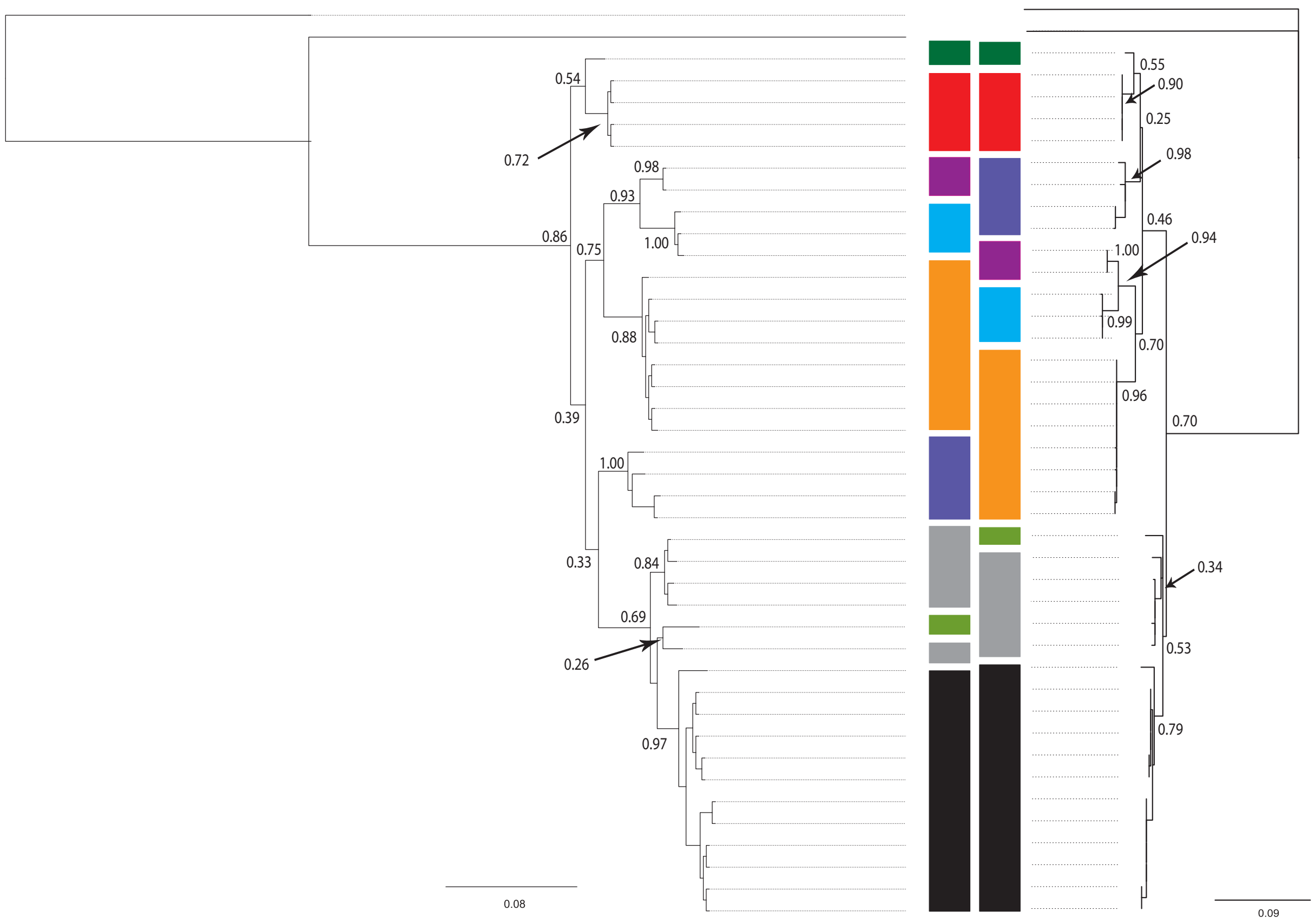




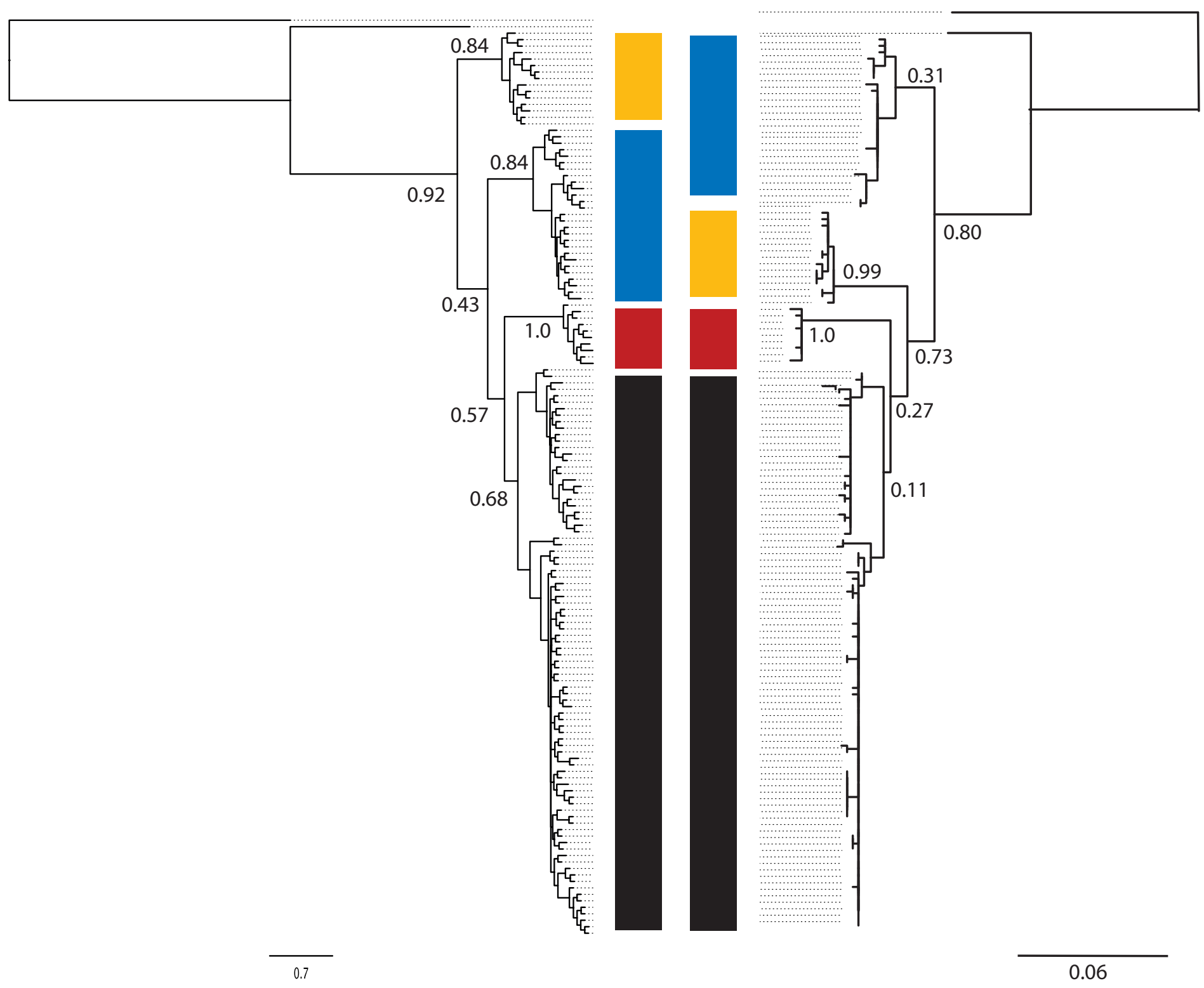

